\title{
Hierarchical Structure and Molecular Dynamics of Metal-Organic Framework as Characterized by Solid State NMR
}

\author{
Wei Chen, Yi-nan Wu, and Fengting Li \\ State Key Lab of Pollution Control and Resource Reuse Study, College of Environmental Science and Engineering, \\ Tongji University, Shanghai 200092, China \\ Correspondence should be addressed to Fengting Li; fengting@mail.tongji.edu.cn
}

Received 25 August 2016; Accepted 29 September 2016

Academic Editor: Josefina Pons

Copyright (C) 2016 Wei Chen et al. This is an open access article distributed under the Creative Commons Attribution License, which permits unrestricted use, distribution, and reproduction in any medium, provided the original work is properly cited.

Metal-organic framework (MOF) stands out as a promising material with great potential in application areas, such as gas separation and catalysis, due to its extraordinary properties. In order to fully characterize the structure of MOFs, especially those without single crystal, Solid State NMR (SSNMR) is an indispensable tool. As a complimentary analytical technique to X-ray diffraction, SSNMR could provide detailed atomic level structure information. Meanwhile, SSNMR can characterize molecular dynamics over a wide dynamics range. In this review, selected applications of SSNMR on various MOFs are summarized and discussed.

\section{Introduction}

Metal-organic framework, or MOF, consisting of metal ion center and organic ligand attracts numerous attention since 1990s [1]. As an inorganic and organic hybrid, MOF owns extraordinary properties, such as ultrahigh internal surface area, tunable internal core size and high thermal stability. The modification of the organic ligand could further provide us with an excellent platform to adjust surface properties for proper applications. Due to these excellent characteristic features, MOFs own great potential in various application areas such as gas storage (i.e., $\mathrm{CO}_{2}, \mathrm{CH}_{4}$, and $\mathrm{H}_{2}$ ) [2-4], separation [5], catalysis [6], and biomedicine [7].

The macroscopic performance of MOFs is highly related to microscopic structure and dynamics. The understanding of this relationship is crucial for us to optimize current MOFs or design new MOFs. For MOF structure, although the crystal structure of many MOFs can be determined through single crystal X-ray diffraction, for numerous MOF systems, such as the porous aluminum terephthalate (MIL53) [8], it is difficult to obtain single crystal and the structural information always need to be refined based on powder Xray diffraction results. Therefore, other techniques that can access to molecular level atomic position are necessary to refine the existing crystal structure. For MOF dynamics, it is required to obtain molecular dynamics information of MOFs at elevated temperature or under different pressure for industrial application. For instance, in the case of the storage of $\mathrm{CO}_{2}$, it is necessary to obtain direct information about the interaction between $\mathrm{CO}_{2}$ and $\mathrm{MOFs}$ and $\mathrm{CO}_{2}$ adsorption dynamics [9].

Solid State NMR (SSNMR) technique stands out as an analytical technique to characterize both local structure and dynamics and the interplay between them [10-12]. SSNMR is able to probe internuclear distance based on various interactions such as dipolar coupling, quadrupolar interaction, and chemical shift anisotropy (CSA). As a result, SSNMR could provide detailed local packing structure and short range ordering information, as a complimentary technique to Xray diffraction [13]. This work provides a brief review of the application of SSNMR in characterizing both structure and dynamics of MOFs with selected examples.

\section{Investigation of MOF Structure by SSNMR}

2.1. Identification of Complex State of Central Metal Ion. The local environment of central metal ion is the crucial information to determine the MOFs' structure. Also, processes, 
TABLE 1: Selected metal ions with different NMR properties ${ }^{\mathrm{b}}$.

\begin{tabular}{|c|c|c|c|c|c|}
\hline Isotope & Spin $I$ & $\begin{array}{l}\text { Natural abundance } \\
\text { (\%) }\end{array}$ & Receptivity $^{\mathrm{a}}$ & $\begin{array}{c}v_{0} \text { at } \mathbf{B}_{0}=11.7 \mathrm{~T} \\
(\mathrm{MHz})\end{array}$ & $\begin{array}{l}\text { Quadrupole moment } \\
\qquad / \mathrm{mb}\end{array}$ \\
\hline${ }^{27} \mathrm{Al}$ & $5 / 2$ & 100 & 0.207 & 130 & 146.6 \\
\hline${ }^{45} \mathrm{Sc}$ & $7 / 2$ & 100 & 0.302 & 121 & -220 \\
\hline${ }^{69} \mathrm{Ga}$ & $3 / 2$ & 60 & 0.0419 & 120 & 171 \\
\hline${ }^{71} \mathrm{Ga}$ & $3 / 2$ & 40 & 0.0571 & 152 & 107 \\
\hline${ }^{25} \mathrm{Mg}$ & $5 / 2$ & 10 & 0.000268 & 31 & 199.4 \\
\hline${ }^{47} \mathrm{Ti}$ & $5 / 2$ & 7.44 & 0.000156 & 28 & 302 \\
\hline${ }^{49} \mathrm{Ti}$ & $7 / 2$ & 5.41 & 0.000205 & 28 & 247 \\
\hline${ }^{91} \mathrm{Zr}$ & $5 / 2$ & 11.22 & 0.00107 & 47 & 176 \\
\hline${ }^{67} \mathrm{Zn}$ & $5 / 2$ & 4.1 & 0.000118 & 31 & 150 \\
\hline
\end{tabular}

a: relative to ${ }^{1} \mathrm{H}=1.00$; b: all data are adapted from https://www.webelements.com.

such as absorption of gas and hydration/dehydration, could change the local structure of central metal ion. This leads to the change of metal ion NMR spectroscopy. Therefore, SSNMR of various metal ions will be first presented.

Table 1 lists selected NMR active metal ions with basic NMR properties including spin number $I$, natural abundance, receptivity, Larmor frequency $v_{0}$ (at magnetic field strength $\boldsymbol{B}_{0}=11.7 \mathrm{~T}$ ), and quadrupole moment $Q$. And detailed description of these properties of each nucleus and selected examples of application are discussed as follows.

${ }^{27} \mathrm{Al} \mathrm{SSNMR} .{ }^{27} \mathrm{Al}$ SSNMR is one of the most studied metal ions due to its high receptivity (relative to ${ }^{1} \mathrm{H}$ ) and moderate quadrupolar interaction. Similar to other metal ions with spin $I>1 / 2,{ }^{27} \mathrm{Al}(5 / 2)$ SSNMR spectrum is characterized by quadrupolar coupling constant $\left(C_{Q}\right)$ and asymmetry parameter $\eta$ representing the electric field gradient (EFG) of metal ion. Latter reflects the local environment close to the metal ion and can be used to determine the crystal structure or observe the structural change. ${ }^{27} \mathrm{Al}$ SSNMR has been widely used to characterize inorganic materials such as cements [14-17]. Following is selected literature related to $\mathrm{Al}$ based MOF systems.

The aluminum 1,4-benzenedicarboxylate (BDC) based MIL-53 is one of the attractive MOFs which has great potential in gas separation and hydrogen storage due to its very large breathe effect [18]. As shown in Figure 1, there are three different forms of MIL-53 (Al) under different treatments: the as-synthesized MIL-53 (Al) (MIL-53as (Al)) contains two BDC molecules in each channel; when MIL53 as $(\mathrm{Al})$ is annealed at high temperature $\left(\sim 330^{\circ} \mathrm{C}\right)$ for three days, the MIL-53 ht (Al) will be obtained without any free BDC molecules in the channel; after cooling to ambient temperature, the MIL-53 lt $(\mathrm{Al})$ is formed with water molecule absorbed inside [8]. Loiseau et al. investigated the MIL-53 (Al) structure changes through ${ }^{27} \mathrm{Al}$ SSNMR as shown in Figure 2 [8]. Figure 2(a) shows ${ }^{27}$ Al SSNMR spectra of MIL$53(\mathrm{Al})$ in different phases. The MIL-53 as (Al) displays a broad shoulder originating from the amorphous $\mathrm{Al}(\mathrm{OH})_{3}$, and, after calcination, ${ }^{27}$ Al SSNMR spectrum becomes shape suggesting more homogeneous systems. Due to large open space created in MIL-53 ht (Al), small molecules such as water are able to be absorbed. Because of well distinct NMR spectra of dehydrated and hydrated MIL-53 (Al), it is able to track the structural transition of MIL-53 (Al) during hydration process. After absorption of guest water molecule, a significant broad ${ }^{27} \mathrm{Al}$ SSNMR spectrum was obtained representing stronger quadrupolar coupling strength. Figure 2(b) shows the in situ observation of the hydration process of MIL$53(\mathrm{Al})$, and the hydration ratio is increased from bottom to top as $0 \%, 30 \%, 50 \%$, and finally $100 \%$. A continuous increase of $C_{Q}$ could be obtained suggesting the break of local symmetry.

Later on, Jiang et al. changed the organic linker BDC into 2-aminobenzene-1,4-dicarboxylic acid (ABDC) and found that the quadrupolar coupling strength $C_{Q}$ decreases $1 \mathrm{MHz}$ indicating more symmetric local structure and more homogeneous charge distribution [19]. They also investigated the dehydration/rehydration process of this MOF. The evolution of ${ }^{27} \mathrm{Al}$ SSNMR spectra upon hydration process is similar to above results. And the broadening of ${ }^{27} \mathrm{Al} \mathrm{NMR}$ resonance line is attributed to the strong interaction formed by guest water molecule (water) and host MOF, especially the hydrogen bonding formed between water and carboxylate.

MIL-118, $\mathrm{Al}_{2}(\mathrm{OH})_{2}\left[\mathrm{C}_{10} \mathrm{O}_{8} \mathrm{H}_{2}\right]$, is a new aluminum pyromellitate developed by Volkringer et al. [20]. The assynthesized MIL-118A, $\mathrm{Al}_{2}(\mathrm{OH})_{2}\left(\mathrm{H}_{2} \mathrm{O}\right)_{2}\left[\mathrm{C}_{10} \mathrm{O}_{8} \mathrm{H}_{2}\right]$, can be transformed into MIL-118B, $\mathrm{Al}_{2}(\mathrm{OH})_{2}\left[\mathrm{C}_{10} \mathrm{O}_{8} \mathrm{H}_{2}\right]$, upon heating. The rehydration of MIL-118B leads to MIL-118C, $\mathrm{Al}_{2}(\mathrm{OH})_{2}\left[\mathrm{C}_{10} \mathrm{O}_{8} \mathrm{H}_{2}\right] \cdot 2.75 \mathrm{H}_{2} \mathrm{O}$. ${ }^{27} \mathrm{Al}$ SSNMR was used to refined the crystal structure of these three phases, and it was found that MIL-118A and B display single ${ }^{27} \mathrm{Al}$ signal, while MIL-118C shows two resonance lines. This suggests $\mathrm{Al}$ is magnetically equivalent in MIL-118 A/B and has two inequivalent sites in MIL-118C, which is consistent with Xray diffraction results. The overlap of NMR signal of different $\mathrm{Al}$ sites induces dramatic difficulties in peak assignment and determination of the composition ratio of different Al. Due to well resolved NMR signal, the multiquantum (MQ) NMR is applied to obtain quadrupolar parameters and isotropic chemical shift of different sites [21-23]. Figure 3 presents the contour plot of $3 \mathrm{Q}$ NMR spectrum of MIL-118A. The 


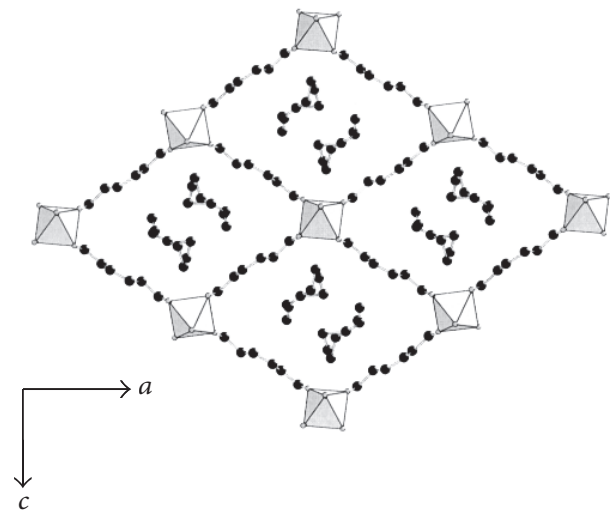

(a)

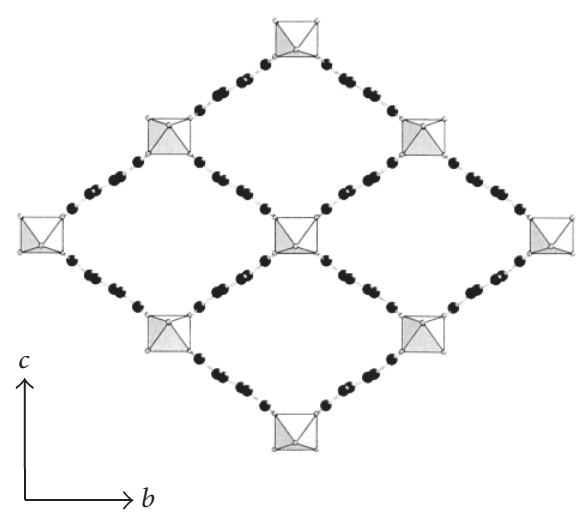

(b)

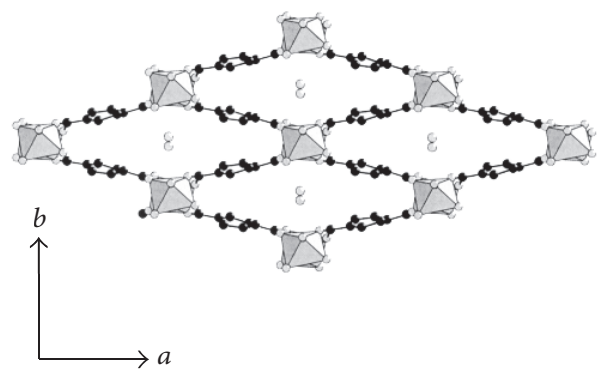

(c)

Figure 1: 3D structure of MIL-53 (Al) in three different states: (a) as-synthesized MIL-53(Al) or MIL-53 as (Al), where two disordered 1-4 benzenedicarboxylic acid molecules are inserted in the channel; (b) calcined MIL-53 ht (Al), where the channel is empty; (c) water saturated MIL-53 lt (Al), where one water molecular locates in the channel. Reprinted with permission from Ref. [8]. Copyright 2004 John Wiley and Sons.

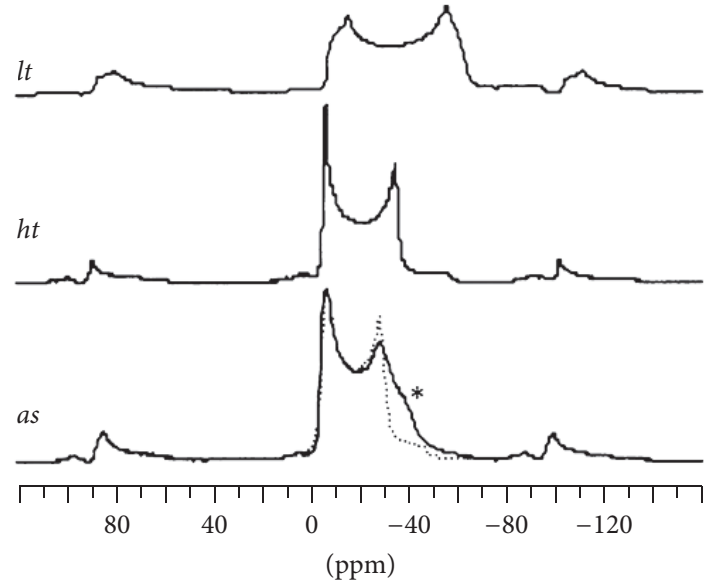

(a)

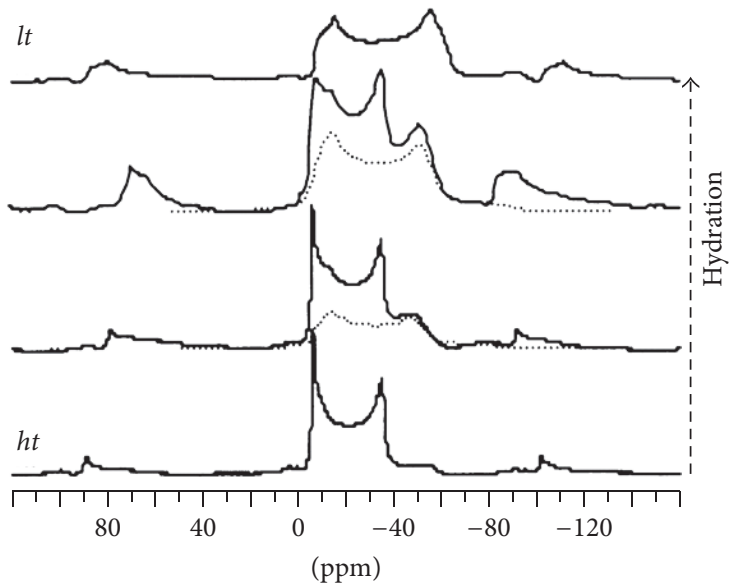

(b)

FIGURE 2: ${ }^{27} \mathrm{Al}$ SSNMR spectra of MIL-53 (Al) in (a) different phases and (b) different hydration content. Reprinted with permission from Ref. [8]. Copyright 2004 John Wiley and Sons. The dot line represents the simulated ${ }^{27} \mathrm{Al} \mathrm{NMR} \mathrm{line} \mathrm{shape} \mathrm{and} * \operatorname{refers}$ to residual $\mathrm{Al}(\mathrm{OH})_{3}$.

multiquantum coherences in one dimension are correlated with central transition (CT) coherence in another dimension. ${ }^{27} \mathrm{Al}$ NMR signals of different sites are well resolved, and relative composition ratio of different species can also be obtained.
${ }^{45}$ Sc SSNMR. Scandium based materials own great potential in the application of catalyst, such as scandium(III) trifluoromethanesulfonate $\left[\mathrm{Sc}(\mathrm{OTf})_{3}\right]$, which can be used to catalyze the carbon-carbon bond-forming reaction in aqueous media $[24,25]$. Due to its good receptivity and moderate 


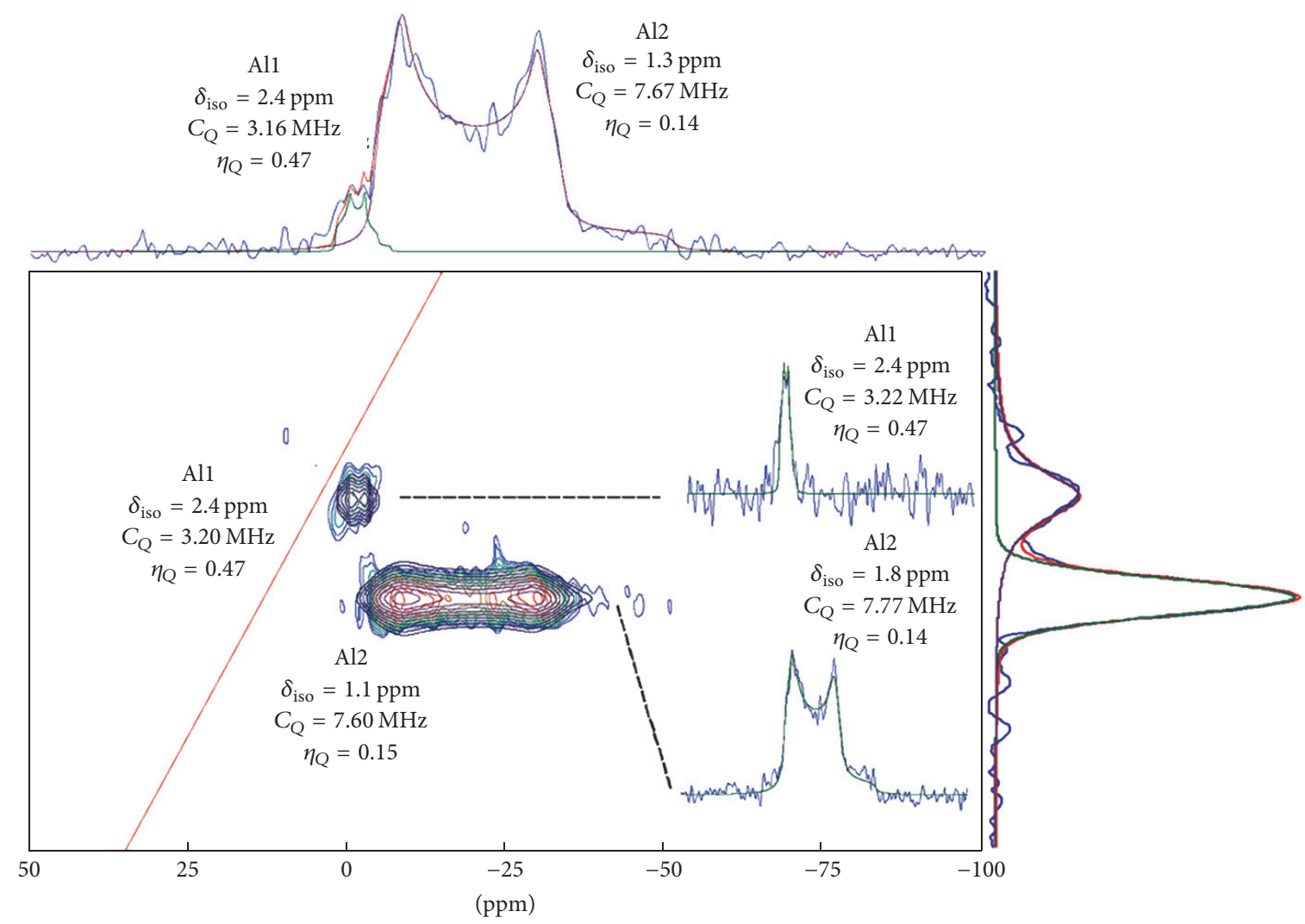

FIGURE 3: Contour plots of ${ }^{27} \mathrm{Al}$ 3QMAS NMR of MIL-118A. Reprinted with permission from Ref. [20]. Copyright 2009 American Chemical Society.

quadrupolar interactions as listed in Table $1,{ }^{45} \mathrm{Sc}$ has good NMR properties. Rossini et al. characterized the $\mathrm{Sc}(\mathrm{OTf})_{3}$ structure through the combination of ${ }^{45} \mathrm{Sc}$ SSNMR and powder X-ray diffraction $[26,27]$. For $\mathrm{Sc}(\mathrm{OTf})_{3}$ it is difficult to obtain single crystal causing dramatic difficulties in structural determination. They chose $\mathrm{Sc}(\mathrm{OAc})_{3}$ as a reference sample due to the well determined crystal structure. Meanwhile, the ${ }^{45} \mathrm{Sc} \mathrm{SSNMR} \mathrm{spectra} \mathrm{of} \mathrm{both} \mathrm{Sc}(\mathrm{OTf})_{3}$ and $\mathrm{Sc}(\mathrm{OAc})_{3}$ are quite similar, and the obtained EFG tensor parameters are almost identical. This suggests that the Sc coordination states are almost the same in both samples. On the basis of the $3 \mathrm{D}$ structure of $\mathrm{Sc}(\mathrm{OAc})_{3}$, the crystal structure of $\mathrm{Sc}(\mathrm{OTf})_{3}$ could be determined through the powder X-ray diffraction pattern.

Besides catalysts, scandium based MOF can also be used in gas separation due to the porous structure. Miller et al. characterized the structure difference between scandium terephthalate, $\mathrm{Sc}_{2}(\mathrm{BDC})_{3}$, and its derivatives, which is able to absorb $\mathrm{CO}_{2}$, through ${ }^{45}$ Sc SSNMR [28]. ${ }^{45} \mathrm{Sc}$ SSNMR spectrum of $\mathrm{Sc}_{2}(\mathrm{BDC})_{3}$ displays a characteristic second-order quadrupolar NMR line shape representing a single site for Sc. However, ${ }^{45}$ Sc SSNMR spectra of its derivatives, aminoand nitro-BDC, display featureless resonance line indicating statistical disorder of the orientation of the functionalized derivatives.

${ }^{69 / 71} \mathrm{Ga}$ SSNMR. Gallium owns two NMR active nucleuses: ${ }^{69} \mathrm{Ga}$ and ${ }^{71} \mathrm{Ga}$ as listed in Table 1 . As compared with
${ }^{71} \mathrm{Ga},{ }^{69} \mathrm{Ga}$ has larger $C_{\mathrm{Q}}$, which displays more broadened line shapes. Therefore, ${ }^{71} \mathrm{Ga}$ is favored in SSNMR experiment. Compared with ${ }^{27} \mathrm{Al},{ }^{71} \mathrm{Ga}$ owns larger second-order quadrupolar splitting $\left(w_{Q}=3 C_{Q} / 4 I(2 I-1)\right)$ due to its low spin number $(I=3 / 2)$. This leads to broader NMR resonance lineshape. Meanwhile, the natural abundance of ${ }^{71} \mathrm{Ga}$ is $40 \%$, while that of ${ }^{27} \mathrm{Al}$ is $100 \%$. Therefore, either NMR sensitivity or resolution of ${ }^{71} \mathrm{Ga}$ is lower than those of ${ }^{27} \mathrm{Al}$. In order to overcome these deficiencies, several software (new pulse sequence) and hardware (fast magic angle spinning, MAS) techniques are utilized. Summary of these techniques can be found in relevant reviews [29].

Hajjar et al. investigated ${ }^{71} \mathrm{Ga}$ coordination environment in MIL-120 and MIL-124 through CT (central transition) MAS [30] NMR in conventional NMR probe [31]. In combination of the NMR simulation SIMPSON [32] and 2D slow-CTMAS results, EFG parameters of different crystallographic $\mathrm{Ga}$ sites are determined; there are two distinct $\mathrm{Ga}$ sites in MIL-120 and one in MIL-124 with remaining site undetectable due to fast molecular motion. This paper shows that classical NMR probe without ultrahigh magnetic field and ultrahigh spinning rate can also be used to detect ${ }^{71} \mathrm{Ga}$ NMR signal and extract useful structural information. Ash and Grandinetti systematically investigated ${ }^{69 / 71} \mathrm{Ga}$ SSNMR in different coordination state [33]. With the aid of ultrafast MAS spinning rate $(30 \mathrm{kHz})$, the whole spectra of ${ }^{69 / 71} \mathrm{Ga}$ 
NMR are able to be obtained. The isotropic chemical shift of ${ }^{69 / 71} \mathrm{Ga}$ is found to be highly dependent on the coordination state: four coordinates lead to $50 \mathrm{ppm}$ and six coordinates result in $225 \mathrm{ppm}$. Volkringer et al. studied gallium trimesate (MIL-96) through ${ }^{71} \mathrm{Ga}$ SSNMR in high magnetic field [34]. ${ }^{71} \mathrm{Ga}$ SSNMR spectrum in the magnetic field strength $\mathbf{B}_{0}$ $=14.1 \mathrm{~T}$ shows a featureless single resonance line. However, under the higher $\mathbf{B}_{0}=17.6 \mathrm{~T}$, two distinct ${ }^{71} \mathrm{Ga}$ signals can be observed. This enable us to extract the isotropic chemical shift and EFG parameters to identify different Ga sites in MOF system.

${ }^{25} \mathrm{Mg} /{ }^{47 / 49} \mathrm{Ti} /{ }^{91} \mathrm{Zr} /{ }^{67} \mathrm{Zn}$ SSNMR. Despite above nucleuses, other frequently used metal ions in MOFs such as ${ }^{25} \mathrm{Mg}$, ${ }^{47 / 49} \mathrm{Ti},{ }^{91} \mathrm{Zr}$, and ${ }^{67} \mathrm{Zn}$ in MOFs experience more severe problems in NMR signal and sensitivity. As shown in Table 1, the natural abundance of these nucleuses is quite low $(<12 \%)$. This requires more NMR experiment time to get a NMR spectrum with an acceptable signal-to-noise ratio. Moreover, the low gyromagnetic ratio $\gamma$ (with corresponding Larmor frequency $<50 \mathrm{MHz}$ at $11.7 \mathrm{~T}$ ) is beyond classical NMR probe sensitive range and large quadrupolar interactions $(Q>150 \mathrm{MB})$ leads to broad quadrupolar lineshape. These unfavorable factors result in the low receptivity $(<0.001)$. Therefore, both NMR sensitivity and resolution are extremely poor. To overcome these problems, ultrahigh magnetic field, ultrafast MAS spinning rate $(\gg 10 \mathrm{kHz})$, and sensitivity enhancement techniques are necessary.

Huang's group used ${ }^{25} \mathrm{Mg}$ SSNMR to investigate the magnesium based MOF systems at high magnetic field $(21.1 \mathrm{~T})[35,36]$. The dehydration and rehydration process of CPO-27-Mg was in situ observed through ${ }^{25} \mathrm{Mg}$ SSNMR [35]. The dehydration process leads to broadened ${ }^{25} \mathrm{Mg}$ SSNMR lineshape indicating that the system becomes more disordered. And the dehydrated MOF presents featureless ${ }^{25} \mathrm{Mg}$ NMR signal, which comes from the large $C_{\mathrm{Q}}$ resulted from the distorted symmetry.

In literature, ${ }^{47,49} \mathrm{Ti}$ SSNMR was normally obtained through sensitivity enhancement pulse sequences, such as fast amplitude-modulated pulse trains [37] or high magnetic field $[16,38,39]$. Due to almost the same Larmor frequency, ${ }^{47} \mathrm{Ti}$ and ${ }^{49} \mathrm{Ti}$ NMR signals always overlap with each other. Gervais et al. investigated the phase distribution of Titania nanoparticle through ${ }^{47,49} \mathrm{Ti}$ SSNMR. Due to different isotropic chemical shift and EFG parameters for different $\mathrm{Ti}$, ${ }^{47,49} \mathrm{Ti}$ SSNMR can be used to get quantitative information of different Ti species with different local symmetry. Rossini et al. studied Titanocene Chlorides through the combination of ${ }^{47,49} \mathrm{Ti}$ SSNMR and quantum chemical calculation [39]. In this case, ${ }^{47} \mathrm{Ti}$ and ${ }^{49} \mathrm{Ti}$ NMR spectra were observed separately at 21.1 T. The obtained NMR line shape together with EFG parameters and chemical shift (CS) tensors clarifies the Ti local structure and the symmetry.

${ }^{91} \mathrm{Zr}$ SSNMR was first reported in 1991 to investigate synthetic oxide materials [40]. ${ }^{91} \mathrm{Zr}$ SSNMR line shape was found to be highly dependent on local symmetry. Zhu et al. investigated ${ }^{91} \mathrm{Zr}$ SSNMR in two zirconium silicates AM-2 and AV-3 [41]. It was found that not only the local symmetry and distortion of the $\left[\mathrm{ZrO}_{6}\right]$ but also the second and third spheres of atoms could influence NMR line shape. This shows that the quadrupolar interaction and CS tensor could also reflect surrounding environment.

Sutrisno et al. studied $\mathrm{Zn}$-contained MOFs (zeolitic imidazolate frameworks ZIF-8, ZIF-14, ZIF- 4, and ZIF-7) through ${ }^{67} \mathrm{Zn}$ SSNMR [42]. The ${ }^{67} \mathrm{Zn}$ NMR line shape is determined not only by the local environment but also by the guest molecules. In combination with molecular dynamics, detailed information of the distribution and dynamics of guest molecules can be obtained. This paper, for the first time, shows the potential of ${ }^{67} \mathrm{Zn}$ SSNMR in determining the detailed structure of Zinc based MOFs as a powerful complimentary characterization tool to X-ray diffraction.

2.2. Identity of Organic Linker. Despite the central metal ion, another important building block of MOFs is organic linker, or organic ligand. The organic linker is mostly constituted by carbon, proton, and oxygen. ${ }^{13} \mathrm{C}$ and ${ }^{1} \mathrm{H}$ SSNMR are frequently used to identify the presence or absence of certain functional groups. As shown in Figure $4,{ }^{13} \mathrm{C}$ and ${ }^{1} \mathrm{H}$ NMR spectra of MIL-53 in different phases display characteristic NMR line features [8]. ${ }^{13} \mathrm{C}$ direct polarization (DP) MAS NMR spectrum could provide quantitative information of ${ }^{13} \mathrm{C}$ of different functional groups as the integrated intensity is proportional to the number of ${ }^{13} \mathrm{C}$. As shown in Figure 4(a), MIL-53 as (Al) displays relatively broad NMR resonance line suggesting the heterogeneity of the system. However, after thermal treatment at high temperature, a narrow and sharp ${ }^{13} \mathrm{C}$ resonance line could be observed suggesting a highly ordered structure with high crystallinity. Further incorporation of guest molecules (i.e., water) broadens and shifts NMR resonance line indicating strong interaction between host (MIL-53) and guest (water) molecules. ${ }^{13} \mathrm{C}$ cross polarization (CP) MAS NMR, most of the time, provides us with qualitative information about different ${ }^{13} \mathrm{C}$ species due to the cross polarization efficiency highly relying on the interaction between observed ${ }^{13} \mathrm{C}$ and neighboring ${ }^{1} \mathrm{H}$, which can be modulated by various factors, such as internuclear distance and molecular motion. As shown in Figure 4(b), when incorporated with guest molecule (water), the carbonyl carbon NMR signal almost disappears as a result of lower CP efficiency caused by the enhanced molecular motions.

${ }^{1} \mathrm{H}$ SSNMR usually suffers from poor resolution resulting from the small chemical shift range and strong homonuclear dipolar coupling $(\sim 60 \mathrm{kHz})$. With great advances in both hardware (i.e., fast MAS $>30 \mathrm{kHz}$ ) and software (new pulse sequence), the NMR resolution of proton spectrum has been largely increased. Nowadays, ${ }^{1} \mathrm{H}$ SSNMR has been widely used to study complicated systems, such as supramolecules [43-45] and biological areas [46-49]. As shown in Figure 4(c), up to three distinct proton signals can be obtained in MIL-53 as (Al). Upon thermal treatment, the free carboxylic acid is completely removed, and further hydration treatment introduces the signal of water. Meanwhile, the hydroxyl group, Al-OH-Al, is directly observed throughout all three samples. 


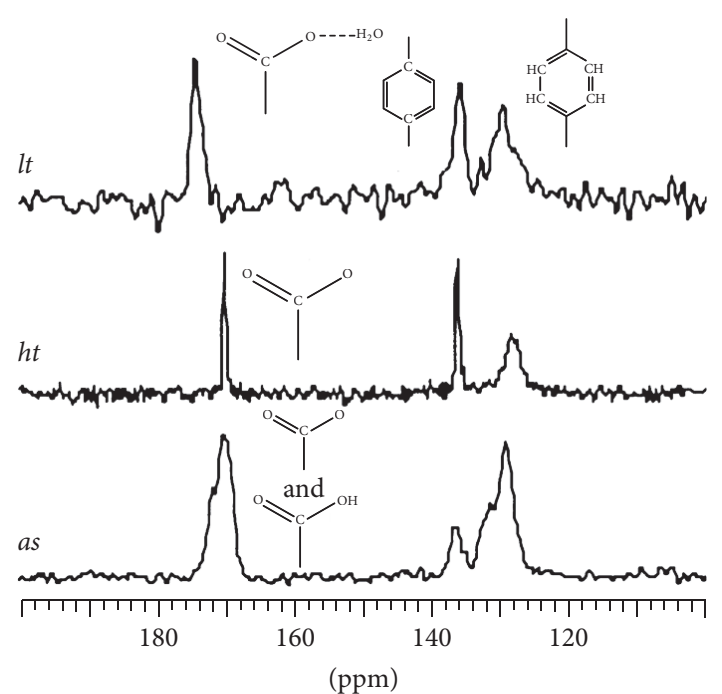

(a)

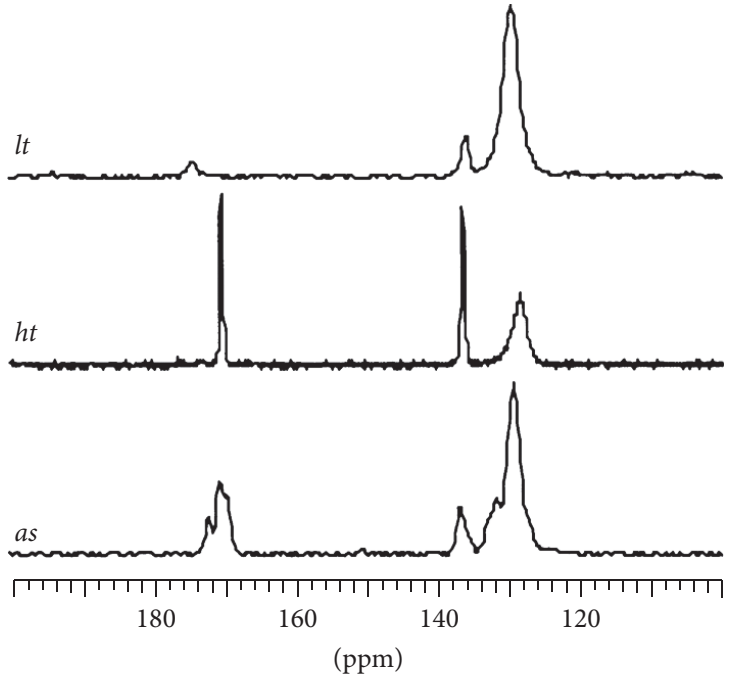

(b)

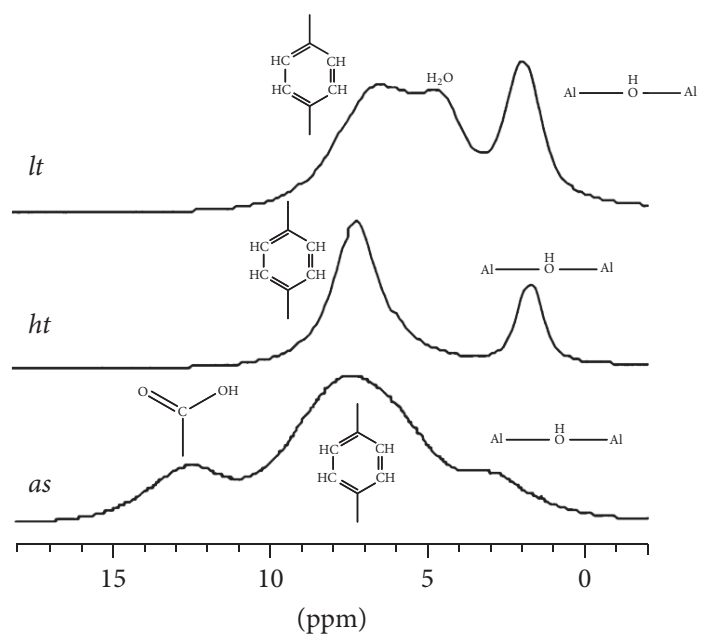

(c)

Figure 4: (a) ${ }^{13}$ C DPMAS NMR spectrum, (b) ${ }^{13} \mathrm{C}$ CPMAS NMR spectrum, and (c) ${ }^{1} \mathrm{H}$ MAS NMR spectrum of MIL-53 in different phases. Reprinted with permission from Ref. [8]. Copyright 2004 John Wiley and Sons.

Some MOFs contain paramagnetic metal center such as $\mathrm{Cu}_{3}(\mathrm{BTC})_{2}$ (copper (II) benzene 1,3,5-tricarboxylate) [50]. The introduction of paramagnetic ions could largely influence the local magnetic field [51]. It will change the ${ }^{1} \mathrm{H}$ and ${ }^{13} \mathrm{C}$ chemical shift, broaden the NMR resonance line, and reduce the spin-lattice relaxation time [52]. Gul-E-Noor et al. found that the proton signal of water absorbed by $\mathrm{Cu}_{3}(\mathrm{BTC})_{2}$ can shift downfield about $7.0 \mathrm{ppm}[50]$. For ${ }^{13} \mathrm{C}$ SSNMR spectrum, signal of aromatic part shifts downfield of 98-92 ppm, while that of the carbonyl carbon shifts upfield of $\sim 300 \mathrm{ppm}$. The possible origin of such difference is ascribed to closer interaction of copper and carboxylic groups.

Oxygen is another frequently encountered atom in MOFs as organic carboxylate ligand is an important building block for many MOFs. Also, other functional groups such as hydroxyl (-OH-), oxygen anion $\left(\mathrm{O}^{2-}\right)$ interacting with metal ions, and guest molecules (i.e., water) contain oxygen atom.
However, the only NMR active isotope is ${ }^{17} \mathrm{O}$, whose natural abundance is $0.038 \% .{ }^{17} \mathrm{O}$ enrichment is necessary to do ${ }^{17} \mathrm{O}$ SSNMR leading to high cost. As a result, little literature about ${ }^{17}$ O SSNMR of MOFs has been reported. He et al. reported an innovative method to prepare ${ }^{17} \mathrm{O}$ enriched MOFs and characterize ${ }^{17} \mathrm{O}$ of different sites through SSNMR [53]. ${ }^{17} \mathrm{O}$ enriched MOFs are prepared through incorporating ${ }^{17} \mathrm{O}$ atom from $\mathrm{H}_{2}{ }^{17} \mathrm{O}$. The EFG parameters and chemical shift tensor information can be obtained through ${ }^{17} \mathrm{O}$ SSNMR. Thus providing detailed structural information and identification of different oxygen contained species.

\section{Investigation of Dynamics in MOF by SSNMR}

Molecular dynamics is another key aspect for materials scientist to understand the correlation between microscopic 


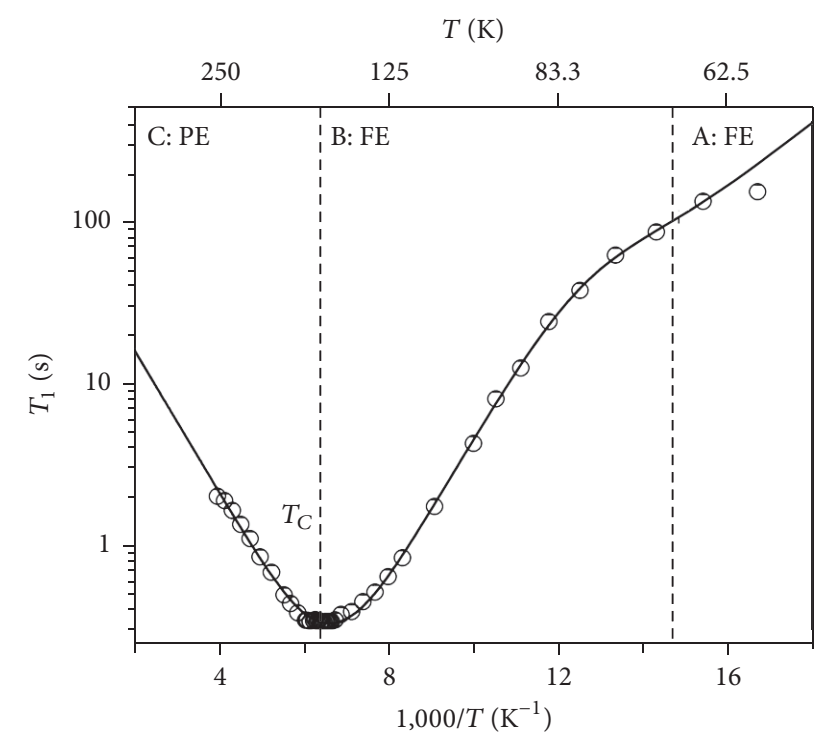

Figure 5: The proton $T_{1}$ as a function of the inverse temperature $T^{-1}$. A, B, and C refer to glassy, ferroelectric (FE), and paraelectric (PE) states. And two characteristic temperatures are $40 \mathrm{~K}$ and $156 \mathrm{~K}$. Reprinted with permission from Ref. [56]. Copyright 2011 PNAS.

and macroscopic properties. A thorough understanding of molecular dynamics requires characterization dynamics range of various techniques which can cover up to 14 orders of magnitude $\left(10^{-12}-10^{2} \mathrm{~s}\right)$. SSNMR is one of the most frequently utilized techniques to characterize the molecule dynamics through relaxation or different anisotropic interactions (i.e., CSA and dipole-dipole interaction). Numerous reviews have been reported elsewhere [10-12, 54, 55]. Here only selected literature is reported to show how SSNMR can be used to characterize different functional groups in MOFs.

3.1. Phase Transition as Investigated by Proton Spin-Lattice Relaxation. Organic linker of MOFs always performs ultrafast dynamics $\left(\left\langle\tau_{c}\right\rangle<10^{-10}\right.$ s) at ambient temperature. Proton spin-lattice relaxation $\left(T_{1}\right)$ is able to probe such fast dynamics. Besara et al. investigate the phase transition and glassy behavior of $\left[\left(\mathrm{CH}_{3}\right)_{2} \mathrm{NH}_{2}\right] \mathrm{Zn}(\mathrm{HCOO})_{3}$ [56]. This MOF takes an order-disorder transition at $156 \mathrm{~K}$. The cationic $\left[\left(\mathrm{CH}_{3}\right)_{2} \mathrm{NH}_{2}\right]^{+}\left(\mathrm{DMA}^{+}\right)$is used as a probe to track the phase transition behavior. As shown in Figure 5, the minima of $T_{1}$ detected at $156 \mathrm{~K}$ is assigned to the order-disorder transition, and the shoulder observed at $40 \mathrm{~K}$ is attributed to the transition of the glassy phase to ferroelectric (FE) phase. Below $40 \mathrm{~K}$, the motion of the methyl group is frozen. The "memory effect" was observed at the range of 65-150 K range as shown by $T_{1}$ difference resulted from different pathways.

Morris et al. utilized proton spin-lattice relaxation method to probe dynamics of organic linkers in IRMOF$3\left(\mathrm{Zn}_{4} \mathrm{O}\left(\mathrm{BDC}-\mathrm{NH}_{2}\right)_{3}\right)$ [57]. Besides ${ }^{1} \mathrm{H} T_{1}$, the spin-lattice relaxation in the rotating frame $\left(T_{1 \rho}\right)$ under a fixed spinlocking field was also used to investigate dynamics of different groups. Different from $T_{1}$, which is sensitive to ultrafast dynamics $(\sim \mathrm{MHz}), T_{1 \rho}$ could detect dynamics $\sim 10 \mathrm{kHz}$. Due to well resolved proton signal of amino and phenyl groups, molecular dynamics of each functional group can be determined. Their finding reveals that the amino group performs rotation with low activated energy and the central phenyl group (BDC) performs $\pi$ flip motion with an activation energy of $21 \mathrm{~kJ} / \mathrm{mol}$.

3.2. Deuterium $\left({ }^{2} \mathrm{H}\right)$ NMR Spectroscopy. Deuterium $\left({ }^{2} \mathrm{H}\right)$ SSNMR is a versatile NMR technique to characterize the molecular dynamics with high resolution and sensitivity. Different from above metal ions, deuterium NMR is dominated by the first-order quadrupolar interaction. The quadrupolar echo pulse is used to obtain an undistorted anisotropic spectrum [58]. Due to its simple pulse sequence and data acquisition, deuterium NMR owns wide application, even in industrial areas [59]. Various ${ }^{2} \mathrm{H}$ NMR techniques, including 1D lineshape analysis and 2D exchange spectroscopy, have been applied to characterize segmental dynamics of glassy polymers $\left(10^{-6}-10^{2} \mathrm{~s}\right)[59,60]$. Therefore, deuterium SSNMR could be used to investigate the dynamics of different functional groups in MOFs.

Bureekaew et al. investigated the aluminum MOFs with high conductivity through imidazole as a proton-carrier molecule [61]. Two similar Al MOFs, $[\mathrm{Al}(\mu 2-\mathrm{OH})(1,4-\mathrm{ndc})]_{n}$ (1) and $[\mathrm{Al}(\mu 2-\mathrm{OH})(1,4-\mathrm{bdc})]_{n}(2)$, show dramatic conductivity difference; MOF 1 has higher proton conductivity than MOF 2. They used ${ }^{2} \mathrm{H}$ SSNMR to investigate the dynamics of imidazole in different porous systems. As shown in Figure $6,{ }^{2} \mathrm{H}$ SSNMR spectrum of imidazole-d4 in MOF 2 at $20^{\circ} \mathrm{C}$ shows Pake-type doublet pattern suggesting anisotropic motion of adsorbed imidazole-d4, while that in MOF 1 displays an extra Lorentzian-type peak located at the middle positon. This indicates isotropic motion of imidazole-d4. The comparison between MOFs $\mathbf{1}$ and $\mathbf{2}$ shows that the adsorbed imidazole owns different dynamics characteristic especially at higher temperature; imidazole performs fast and isotropic motion in MOF 1 while it remains unchanged in MOF 2. Such dynamics difference is associated with the proton conductivity difference, and the proton conducting pathway is also determined to be proton-hopping mechanism.

3.3. Chemical Shift Anisotropy. The NMR signal in solid state is orientation dependent [62]. For certain nucleus, such as ${ }^{13} \mathrm{C}$, this interaction is named chemical shift anisotropy (CSA) and can be used to probe molecular dynamics $\left(10^{-3}-\right.$ $\left.10^{2} \mathrm{~s}\right)$. For MOFs, as mentioned in the introduction, one of the most promising applications is the capture and storage of guest molecules, such as $\mathrm{CO}_{2}$. A molecular level understanding of the binding and dynamics of these guest molecules is necessary to refine current MOFs.

Kong et al. for the first time uses SSNMR to characterize the binding and molecular dynamics of $\mathrm{CO}_{2}$ in $\mathrm{Mg}-\mathrm{MOF}-$ $74(\mathrm{Mg} 2$ (dobdc) (H4dobdc $=2,5$-dihydroxyterephthalic acid) [9]. $\mathrm{CO}_{2}$ is ${ }^{13} \mathrm{C}$ enriched in order to obtain good signal-tonoise ratio. The temperature dependence of CSA patterns is acquired together with CSA simulation in order to obtain quantitative information about the molecular orientation of $\mathrm{CO}_{2} \cdot \mathrm{CO}_{2}$ is found to perform uniaxial rotation close to 

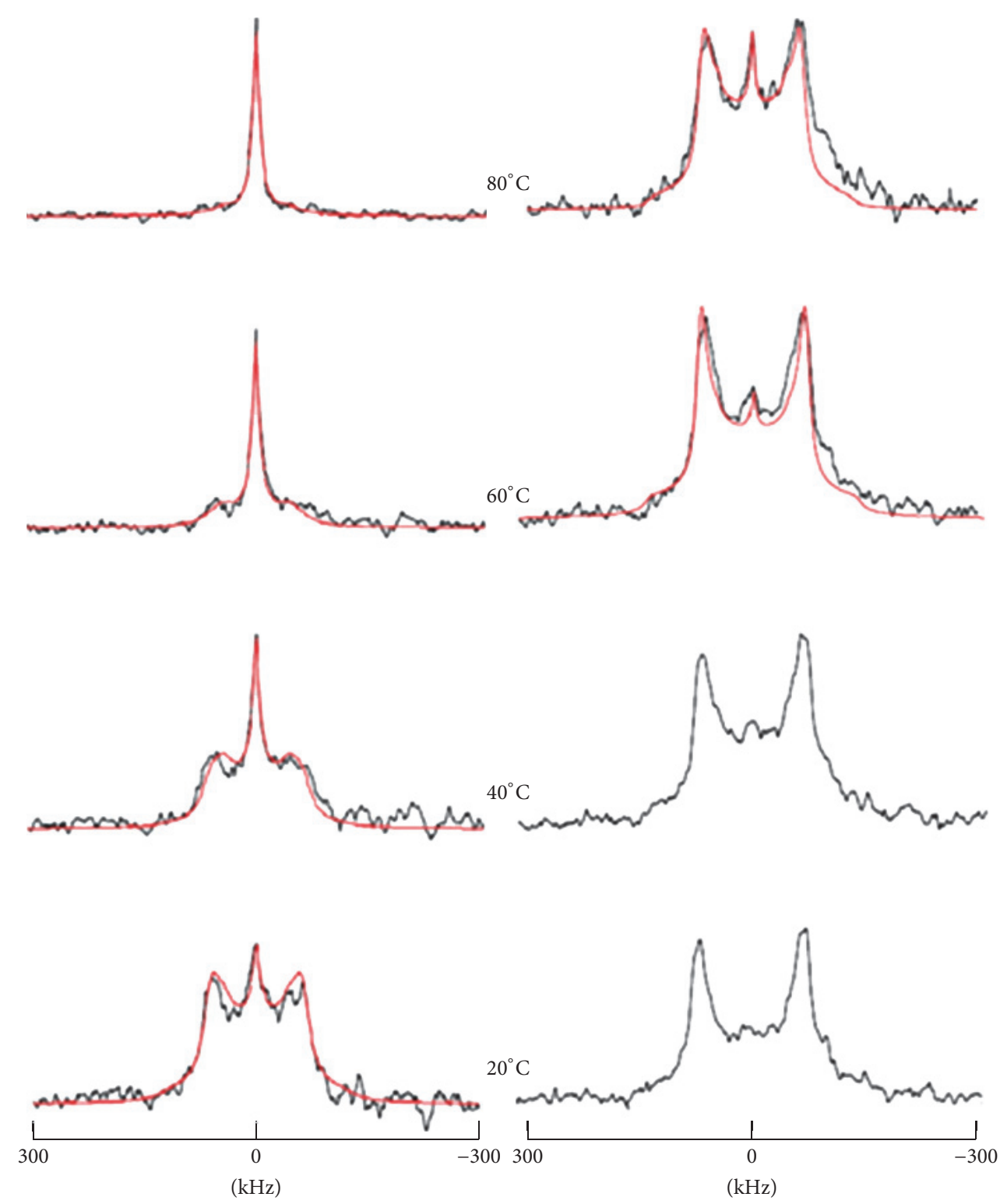

Figure 6: ${ }^{2} \mathrm{H}$ NMR of $[\mathrm{Al}(\mu 2-\mathrm{OH})(1,4-\mathrm{ndc})]_{n}$ (1,4-ndc: 1,4-naphthalenedicarboxylate) [66] and $[\mathrm{Al}(\mu 2-\mathrm{OH})(1,4-\mathrm{bdc})]_{n}$ (1,4-bdc: $1,4-$ benzenedicarboxylate) loaded with imidazole-d4 molecules [61]. Reprinted with permission from Ref. [61]. Copyright 2009 Nature Publishing Group.

$\mathrm{Mg}^{2+}$ site at a relatively fixed angle. Zhang et al. systematically investigated the molecular dynamics of guest molecule $\left(\mathrm{CO}_{2}\right)$ in various MIL-53 through SSNMR [63]. The temperature dependent CSA pattern of ${ }^{13} \mathrm{C}\left({ }^{13} \mathrm{CO}_{2}\right)$ reveals the wobbling and hopping behavior of $\mathrm{CO}_{2}$ within MIL-53. The change of metal ion (from $\mathrm{Al}$ to $\mathrm{Ga}$ ) could change CSA pattern suggesting the binding strength change, which is later confirmed by ${ }^{1} \mathrm{H}_{-}{ }^{13} \mathrm{C}$ CP SSNMR.

Despite porous MOF systems, the host-guest interaction also exists in some nonporous crystal at high temperature. The $\mathrm{CO}_{2}$ sorption process in these crystals is difficult to be observed due to its rapid motion. Bin et al. use synchrotron powder X-ray diffraction and SSNMR to investigate the restrained motion of $\mathrm{CO}_{2}$ in the small cages within the crystal
[64]. The interaction between the host and guest molecules is characterized by ${ }^{1} \mathrm{H}^{-13} \mathrm{C}$ HETCOR. The $\mathrm{CO}_{2}$ molecules are found to be located between the outer phenyl rings of host molecule $\mathrm{H}_{3} \mathrm{BTB}$ and the DMF molecules. Similar to above mentioned MOFs, the incorporation and molecular dynamics of $\mathrm{CO} 2$ are investigated through ${ }^{13} \mathrm{C}$ CSA.

\section{Conclusion}

In this review, we briefly summarize different SSNMR work on MOFs. SSNMR is a powerful analytical technique to characterize metal ion center, organic linker, and host-guest interaction as a complimentary technique to X-ray diffraction. Meanwhile, SSNMR can characterize molecular dynamics 
TABLE 2: Application of SSNMR in various MOFs with different techniques.

\begin{tabular}{|c|c|c|c|}
\hline MOF & SSNMR techniques & Information & Reference \\
\hline MIL-53 & ${ }^{27} \mathrm{Al},{ }^{1} \mathrm{H},{ }^{13} \mathrm{C}$ SSNMR & $\begin{array}{l}\text { Structural determination of different phases; } \\
\text { identification of different organic linker }\end{array}$ & {$[8,19]$} \\
\hline MIL-118 & ${ }^{27} \mathrm{Al}$ 3QMAS NMR & $\begin{array}{l}\text { Quantitative determination of } \mathrm{Al} \text { with different } \\
\text { coordinate number }\end{array}$ & {$[20]$} \\
\hline $\mathrm{Sc}_{2}(\mathrm{BDC})_{3}$ & ${ }^{45} \mathrm{Sc}$ SSNMR & Orientation of Sc with different derivatives & {$[28]$} \\
\hline MIL-120 \& MIL-124 & $\begin{array}{l}\text { 2D slow-CTMAS }{ }^{71} \mathrm{Ga} \\
\text { SSNMR }\end{array}$ & Structural determination & {$[31]$} \\
\hline MIL-96 & $\begin{array}{l}{ }^{71} \text { Ga SSNMR in high } \\
\text { magnetic field }\end{array}$ & Structural determination & {$[34]$} \\
\hline CPO-27-Mg & ${ }^{25} \mathrm{Mg}$ SSNMR & $\begin{array}{l}\text { In situ observation of hydration and dehydration } \\
\text { process }\end{array}$ & {$[35,36]$} \\
\hline ZIF-8, ZIF-14, ZIF- 4, ZIF-7 & ${ }^{67} \mathrm{Zn}$ SSNMR & Structural determination & {$[42]$} \\
\hline MIL-125 & ${ }^{47 / 49} \mathrm{Ti}$ SSNMR & $\begin{array}{l}\text { Determination of the presence and absence of guest } \\
\text { molecule }\end{array}$ & {$[65]$} \\
\hline $\mathrm{Cu}_{3}(\mathrm{BTC})_{2}$ & ${ }^{13} \mathrm{C}$ MAS NMR & Influence of $\mathrm{Cu}(\mathrm{II})$ on ${ }^{13} \mathrm{C} \mathrm{NMR}$ & {$[50]$} \\
\hline$\left[\left(\mathrm{CH}_{3}\right)_{2} \mathrm{NH}_{2}\right] \mathrm{Zn}(\mathrm{HCOO})_{3}$ & ${ }^{1} \mathrm{H} T_{1}$ relaxation & Phase transition & {$[56]$} \\
\hline IRMOF-3 & $T_{1 \rho}$ & Molecular dynamics & {$[57]$} \\
\hline $\begin{array}{l}{[\mathrm{Al}(\mu 2-\mathrm{OH})(1,4-\mathrm{ndc})]_{n}} \\
\text { (1) \& }[\mathrm{Al}(\mu 2-\mathrm{OH})(1,4-\mathrm{bdc})]_{n}(2)\end{array}$ & ${ }^{2} \mathrm{H} \mathrm{NMR}$ & Molecular dynamics & {$[61]$} \\
\hline Mg-MOF-74 & $\begin{array}{l}{ }^{13} \mathrm{C} \mathrm{CSA} \text { and }{ }^{13} \mathrm{C}-{ }^{1} \mathrm{H} \\
\text { HETCOR }\end{array}$ & Molecular dynamics and orientation of $\mathrm{CO}_{2}$ & {$[9]$} \\
\hline
\end{tabular}

over a broad range with site specific advantage at a molecular level. Such information can in turn help us understand the origin of some macroscopic performances of MOFs. This could rationalize the molecular design of MOFs. Summary of different MOFs characterized by different SSNMR techniques is shown in Table 2. Admittedly, limited by article length, there is numerous pieces of SSNMR literature of MOFs which is not included in current review. With the increment of applications of MOFs and the great achievement of SSNMR techniques, it will be more convenient for us to obtain molecular information of different functional groups of MOFs, and SSNMR would become an indispensable analytical tool to characterize both structure and dynamics of MOFs.

\section{Competing Interests}

The authors declare that there are no competing interests regarding the publication of this paper.

\section{Acknowledgments}

This work was supported by the Program on Demonstration and Capacity Building of Drinking Water Treatment in EastAfrica by the Ministry of Science and Technology of China (MOST) (KY201402012), the Fundamental Research Funds for the Central Universities, Program for Young Excellent Talents in Tongji University (2014KJ007), Foundation of State Key Laboratory of Pollution Control and Resource Reuse (Tongji University) (PCRRY15007), and the National Nature \& Science Foundation of China (21577100).

\section{References}

[1] H.-C. Zhou, J. R. Long, and O. M. Yaghi, "Introduction to metalorganic frameworks," Chemical Reviews, vol. 112, no. 2, pp. 673674, 2012.

[2] R. B. Getman, Y.-S. Bae, C. E. Wilmer, and R. Q. Snurr, "Review and analysis of molecular simulations of methane, hydrogen, and acetylene storage in metal-organic frameworks," Chemical Reviews, vol. 112, no. 2, pp. 703-723, 2012.

[3] K. Sumida, D. L. Rogow, J. A. Mason et al., "Carbon dioxide capture in metal-organic frameworks," Chemical Reviews, vol. 112, no. 2, pp. 724-781, 2012.

[4] H. Wu, Q. Gong, D. H. Olson, and J. Li, "Commensurate adsorption of hydrocarbons and alcohols in microporous metal organic frameworks," Chemical Reviews, vol. 112, no. 2, pp. 836868, 2012.

[5] J.-R. Li, J. Sculley, and H.-C. Zhou, "Metal-organic frameworks for separations," Chemical Reviews, vol. 112, no. 2, pp. 869-932, 2012.

[6] M. Yoon, R. Srirambalaji, and K. Kim, "Homochiral metalorganic frameworks for asymmetric heterogeneous catalysis," Chemical Reviews, vol. 112, no. 2, pp. 1196-1231, 2012.

[7] P. Horcajada, R. Gref, T. Baati et al., "Metal-organic frameworks in biomedicine," Chemical Reviews, vol. 112, no. 2, pp. 1232-1268, 2012.

[8] T. Loiseau, C. Serre, C. Huguenard et al., "A rationale for the large breathing of the porous aluminum terephthalate (MIL-53) upon hydration," Chemistry - A European Journal, vol. 10, no. 6, pp. 1373-1382, 2004.

[9] X. Kong, E. Scott, W. Ding, J. A. Mason, J. R. Long, and J. A. Reimer, " $\mathrm{CO}_{2}$ dynamics in a metal-organic framework with open metal sites," Journal of the American Chemical Society, vol. 134, no. 35, pp. 14341-14344, 2012. 
[10] M. R. Hansen, R. Graf, and H. W. Spiess, "Interplay of Structure and Dynamics in Functional Macromolecular and Supramolecular Systems As Revealed by Magnetic Resonance Spectroscopy," Chemical Reviews, vol. 116, no. 3, pp. 1272-1308, 2016.

[11] M. R. Hansen, R. Graf, and H. W. Spiess, "Solid-state NMR in macromolecular systems: insights on how molecular entities move," Accounts of Chemical Research, vol. 46, no. 9, pp. 19962007, 2013.

[12] H. W. Spiess, "Interplay of structure and dynamics in macromolecular and supramolecular systems," Macromolecules, vol. 43, no. 13, pp. 5479-5491, 2010.

[13] A. Sutrisno and Y. Huang, "Solid-state NMR: a powerful tool for characterization of metal-organic frameworks," Solid State Nuclear Magnetic Resonance, vol. 49-50, pp. 1-11, 2013.

[14] J. Skibsted, H. J. Jakobsen, and C. Hall, "Direct observation of aluminium guest ions in the silicate phases of cement minerals by ${ }^{27}$ Al MAS NMR spectroscopy," Journal of the Chemical Society, Faraday Transactions, vol. 90, no. 14, pp. 2095-2098, 1994.

[15] J. O. Ehresmann, W. Wang, B. Herreros et al., "Theoretical and experimental investigation of the effect of proton transfer on the ${ }^{27}$ Al MAS NMR line shapes of zeolite-adsorbate complexes: an independent measure of solid acid strength," Journal of the American Chemical Society, vol. 124, no. 36, pp. 10868-10874, 2002.

[16] S. Ganapathy, K. U. Gore, R. Kumar, and J.-P. Amoureux, "Multinuclear $\left({ }^{27} \mathrm{Al},{ }^{29} \mathrm{Si},{ }^{47,49} \mathrm{Ti}\right)$ solid-state NMR of titanium substituted zeolite USY," Solid State Nuclear Magnetic Resonance, vol. 24, no. 2-3, pp. 184-195, 2003.

[17] X. Pardal, F. Brunet, T. Charpentier, I. Pochard, and A. Nonat, "27Al and 29Si solid-state NMR characterization of calciumaluminosilicate-hydrate," Inorganic Chemistry, vol. 51, no. 3, pp. 1827-1836, 2012.

[18] C. Serre, F. Millange, C. Thouvenot et al., "Very large breathing effect in the first nanoporous chromium(III)-based solids: MIL-53 or $\mathrm{Cr}^{I I}(\mathrm{OH}) \cdot \mathrm{O}_{2} \mathrm{C}-\mathrm{C}_{6} \mathrm{H}_{4}-\mathrm{CO}_{2} \cdot \mathrm{HO}_{2} \mathrm{C}-\mathrm{C}_{6} \mathrm{H}_{4}-$ $\mathrm{CO}_{2} \mathrm{H}_{x} \cdot \mathrm{H}_{2} \mathrm{O}_{y}$," Journal of the American Chemical Society, vol. 124, no. 45, pp. 13519-13526, 2002.

[19] Y. Jiang, J. Huang, S. Marx, W. Kleist, M. Hunger, and A. Baiker, "Effect of dehydration on the local structure of framework aluminum atoms in mixed linker MIL-53(Al) materials studied by solid-state NMR spectroscopy," The Journal of Physical Chemistry Letters, vol. 1, no. 19, pp. 2886-2890, 2010.

[20] C. Volkringer, T. Loiseau, N. Guillou et al., "Structural transitions and flexibility during dehydration-rehydration process in the MOF-type aluminum pyromellitate A12(OH)2[C1008H2](MIL-118)," Crystal Growth and Design, vol. 9, no. 6, pp. 2927-2936, 2009.

[21] J. Rocha, C. M. Morais, and C. Fernandez, "Progress in multiplequantum magic-angle spinning NMR spectroscopy," in New Techniques in Solid-State NMR, vol. 246 of Topics in Current Chemistry, pp. 141-194, Springer, Berlin, Germany, 2005.

[22] L. Frydman and J. S. Harwood, "Isotropic spectra of half-integer quadrupolar spins from bidimensional magic-angle spinning NMR," Journal of the American Chemical Society, vol. 117, no. 19, pp. 5367-5368, 1995.

[23] A. Goldbourt and P. K. Madhu, "Multiple-quantum magicangle spinning: high-resolution solid-state NMR of half-integer spin quadrupolar nuclei," Annual Reports on NMR Spectroscopy, vol. 54, pp. 81-153, 2004.

[24] S. Kobayashi and S. Nagayama, "Aldehydes vs aldimines. Unprecedented aldimine-selective nucleophilic additions in the coexistence of aldehydes using a lanthanide salt as a Lewis acid catalyst," Journal of the American Chemical Society, vol. 119, no. 42, pp. 10049-10053, 1997.

[25] S. Kobayashi, M. Sugiura, H. Kitagawa, and W. W.-L. Lam, "Rare-earth metal triflates in organic synthesis," Chemical Reviews, vol. 102, no. 6, pp. 2227-2302, 2002.

[26] A. J. Rossini, M. P. Hildebrand, P. A. Hazendonk, and R. W. Schurko, "Multinuclear solid-state NMR studies of polymersupported scandium triflate catalysts," Journal of Physical Chemistry C, vol. 118, no. 39, pp. 22649-22662, 2014.

[27] A. J. Rossini and R. W. Schurko, "Experimental and theoretical studies of $45 \mathrm{Sc}$ NMR interactions in solids," Journal of the American Chemical Society, vol. 128, no. 32, pp. 10391-10402, 2006.

[28] S. R. Miller, P. A. Wright, T. Devic et al., "Single crystal Xray diffraction studies of carbon dioxide and fuel-related gases adsorbed on the small pore scandium terephthalate metal organic framework, $\mathrm{Sc}_{2}\left(\mathrm{O}_{2} \mathrm{CC}_{6} \mathrm{H}_{4} \mathrm{CO}_{2}\right)_{3}$," Langmuir, vol. 25, no. 6, pp. 3618-3626, 2009.

[29] S. E. Ashbrook and S. Sneddon, "New methods and applications in solid-state NMR spectroscopy of quadrupolar nuclei," Journal of the American Chemical Society, vol.136, no. 44, pp. 1544015456, 2014.

[30] J. Persons and G. S. Harbison, "Slow turning reveals enormous quadrupolar interactions (STREAQI)," Journal of Magnetic Resonance, vol. 186, no. 2, pp. 347-351, 2007.

[31] R. Hajjar, C. Volkringer, T. Loiseau et al., "71Ga Slow-CTMAS NMR and crystal structures of MOF-type gallium carboxylates with infinite edge-sharing octahedra chains (MIL-120 and MIL124)," Chemistry of Materials, vol. 23, no. 1, pp. 39-47, 2011.

[32] M. Bak, J. T. Rasmussen, and N. C. Nielsen, "SIMPSON: a general simulation program for solid-state NMR spectroscopy," Journal of Magnetic Resonance, vol. 147, no. 2, pp. 296-330, 2000.

[33] J. T. Ash and P. J. Grandinetti, "Solid-state NMR characterization of $69 \mathrm{Ga}$ and 71Ga in crystalline solids," Magnetic Resonance in Chemistry, vol. 44, no. 9, pp. 823-831, 2006.

[34] C. Volkringer, T. Loiseau, G. Férey et al., "Synthesis, crystal structure and $71 \mathrm{Ga}$ solid state NMR of a MOF-type gallium trimesate (MIL-96) with $\mu 3$-oxo bridged trinuclear units and a hexagonal 18-ring network," Microporous and Mesoporous Materials, vol. 105, no. 1-2, pp. 111-117, 2007.

[35] J. Xu, V. V. Terskikh, and Y. Huang, " ${ }^{25} \mathrm{Mg}$ solid-state NMR: a sensitive probe of adsorbing guest molecules on a metal center in metal-organic framework CPO-27-Mg," The Journal of Physical Chemistry Letters, vol. 4, no. 1, pp. 7-11, 2013.

[36] J. Xu, V. V. Terskikh, and Y. Huang, "Resolving multiple non-equivalent metal sites in magnesium-containing metalorganic frameworks by natural abundance $25 \mathrm{Mg}$ solid-state NMR spectroscopy," Chemistry - A European Journal, vol. 19, no. 14, pp. 4432-4436, 2013.

[37] T. Bräuniger, P. K. Madhu, A. Pampel, and D. Reichert, "Application of fast amplitude-modulated pulse trains for signal enhancement in static and magic-angle-spinning 47,49Ti-NMR spectra," Solid State Nuclear Magnetic Resonance, vol. 26, no. 34, pp. 114-120, 2004.

[38] C. Gervais, M. E. Smith, A. Pottier, J.-P. Jolivet, and F. Babonneau, "Solid-state 47,49Ti MNR determination of the phase distribution of titania nanoparticles," Chemistry of Materials, vol. 13, no. 2, pp. 462-467, 2001.

[39] A. J. Rossini, I. Hung, and R. W. Schurko, "Solid-state 47/49Ti NMR of titanocene chlorides," Journal of Physical Chemistry Letters, vol. 1, no. 20, pp. 2989-2998, 2010. 
[40] J. S. Hartman, F. P. Koffyberg, and J. A. Ripmeester, "An exploration of $91 \mathrm{Zr}$ solid-state NMR of synthetic oxide materials," Journal of Magnetic Resonance (1969), vol. 91, no. 2, pp. 400404, 1991.

[41] J. Zhu, Z. Lin, Z. Yan, and Y. Huang, " $91 \mathrm{Zr}$ and $25 \mathrm{Mg}$ solid-state NMR characterization of the local environments of the metal centers in microporous materials," Chemical Physics Letters, vol. 461, no. 4-6, pp. 260-265, 2008.

[42] A. Sutrisno, V. V. Terskikh, Q. Shi et al., "Characterization of Zn-containing metal-organic frameworks by solid-state ${ }^{67} \mathrm{Zn}$ NMR spectroscopy and computational modeling," ChemistryA European Journal, vol. 18, no. 39, pp. 12251-12259, 2012.

[43] S. P. Brown, I. Schnell, J. D. Brand, K. Müllen, and H. W. Spiess, "An investigation of $\pi-\pi$ packing in a columnar hexabenzocoronene by fast magic-angle spinning and double-quantum $1 \mathrm{H}$ solid-state NMR spectroscopy," Journal of the American Chemical Society, vol. 121, no. 28, pp. 6712-6718, 1999.

[44] I. Schnell, S. P. Brown, H. Y. Low, H. Ishida, and H. W. Spiess, "An investigation of hydrogen bonding in benzoxazine dimers by fast magic-angie spinning and double-quantum ${ }^{1} \mathrm{H}$ NMR spectroscopy," Journal of the American Chemical Society, vol. 120, no. 45, pp. 11784-11795, 1998.

[45] S. Pawsey, M. McCormick, S. De Paul et al., "1H Fast MAS NMR studies of hydrogen-bonding interactions in self-assembled monolayers," Journal of the American Chemical Society, vol. 125, no. 14, pp. 4174-4184, 2003.

[46] O. C. Andronesi, S. Becker, K. Seidel, H. Heise, H. S. Young, and M. Baldus, "Determination of membrane protein structure and dynamics by magic-angle-spinning solid-state NMR spectroscopy," Journal of the American Chemical Society, vol. 127, no. 37, pp. 12965-12974, 2005.

[47] J. Klein, R. Meinecke, M. Mayer, and B. Meyer, "Detecting binding affinity to immobilized receptor proteins in compound libraries by HR-MAS STD NMR," Journal of the American Chemical Society, vol. 121, no. 22, pp. 5336-5337, 1999.

[48] D. H. Zhou, J. J. Shea, A. J. Nieuwkoop et al., "Solid-state protein-structure determination with proton-detected tripleresonance 3D magic-angle-spinning NMR spectroscopy," Angewandte Chemie-International Edition, vol. 46, no. 44, pp. 8380-8383, 2007.

[49] M. Ernst, A. Detken, A. Böckmann, and B. H. Meier, "NMR spectra of a microcrystalline protein at $30 \mathrm{kHz}$ MAS," Journal of the American Chemical Society, vol. 125, no. 51, pp. 15807-15810, 2003.

[50] F. Gul-E-Noor, B. Jee, A. Pöppl, M. Hartmann, D. Himsl, and M. Bertmer, "Effects of varying water adsorption on a $\mathrm{Cu}_{3}(\mathrm{BTC})_{2}$ metal-organic framework (MOF) as studied by ${ }^{1} \mathrm{H}$ and ${ }^{13} \mathrm{C}$ solid-state NMR spectroscopy," Physical Chemistry Chemical Physics, vol. 13, no. 17, pp. 7783-7788, 2011.

[51] I. J. Lowe and D. Tse, "Nuclear spin-lattice relaxation via paramagnetic centers," Physical Review, vol. 166, no. 2, p. 279, 1968.

[52] S. Ganapathy, A. Naito, and C. A. McDowell, "Paramagnetic doping as an aid in obtaining high-resolution 13C NMR spectra of biomolecules in the solid state," Journal of the American Chemical Society, vol. 103, no. 20, pp. 6011-6015, 1981.

[53] P. He, J. Xu, V. V. Terskikh, A. Sutrisno, H.-Y. Nie, and Y. Huang, "Identification of nonequivalent framework oxygen species in metal-organic frameworks by $17 \mathrm{O}$ solid-state NMR," Journal of Physical Chemistry C, vol. 117, no. 33, pp. 16953-16960, 2013.
[54] M. R. Chierotti and R. Gobetto, "Solid-State NMR studies on supramolecular chemistry," in Supramolecular Chemistry: From Molecules to Nanomaterials, 2012.

[55] H. W. Spiess, "Structure and dynamics of solid polymers from 2D- and 3D-NMR," Chemical Reviews, vol. 91, no. 7, pp. 13211338, 1991.

[56] T. Besara, P. Jain, N. S. Dalal et al., "Mechanism of the orderdisorder phase transition, and glassy behavior in the metalorganic framework $\left[\left(\mathrm{CH}_{3}\right)_{2} \mathrm{NH}_{2}\right] \mathrm{Zn}(\mathrm{HCOO})_{3}$," Proceedings of the National Academy of Sciences of the United States of America, vol. 108, no. 17, pp. 6828-6832, 2011.

[57] W. Morris, R. E. Taylor, C. Dybowski, O. M. Yaghi, and M. A. Garcia-Garibay, "Framework mobility in the metal-organic framework crystal IRMOF-3: evidence for aromatic ring and amine rotation," Journal of Molecular Structure, vol. 1004, no. 1-3, pp. 94-101, 2011.

[58] J. H. Davis, K. R. Jeffrey, M. Bloom, M. I. Valic, and T. P. Higgs, "Quadrupolar echo deuteron magnetic resonance spectroscopy in ordered hydrocarbon chains," Chemical Physics Letters, vol. 42, no. 2, pp. 390-394, 1976.

[59] K. Schmidt-Rohr and H. W. Spiess, Multidimensional SolidState NMR and Polymers, 1994.

[60] U. Pschorn, E. Roessler, H. Sillescu, S. Kaufmann, D. Schaefer, and H. W. Spiess, "Local and cooperative motions at the glass transition of polystyrene. Information from one- and two-dimensional NMR as compared with other techniques," Macromolecules, vol. 24, no. 2, pp. 398-402, 1991.

[61] S. Bureekaew, S. Horike, M. Higuchi et al., "One-dimensional imidazole aggregate in aluminium porous coordination polymers with high proton conductivity," Nature Materials, vol. 8, no. 10, pp. 831-836, 2009.

[62] W. Chen, H.-J. Sun, and T. Miyoshi, "Unique molecular dynamics of structural elements in an asymmetric janus bisamide supramolecule characterized by solid-state NMR," The Journal of Physical Chemistry B, vol. 117, no. 43, pp. 13698-13709, 2013.

[63] Y. Zhang, B. E. Lucier, and Y. Huang, "Deducing $\mathrm{CO}_{2}$ motion, adsorption locations and binding strengths in a flexible metalorganic framework without open metal sites," Physical Chemistry Chemical Physics, vol. 18, no. 12, pp. 8327-8341, 2016.

[64] S. B. Bin, D. Moon, R. Graf et al., "High-temperature in situ crystallographic observation of reversible gas sorption in impermeable organic cages," Proceedings of the National Academy of Sciences of the United States of America, vol. 112, no. 46, pp. 14156-14161, 2015.

[65] P. He, B. E. G. Lucier, V. V. Terskikh et al., "Spies within metalorganic frameworks: investigating metal centers using solidstate NMR," Journal of Physical Chemistry C, vol. 118, no. 41, pp. 23728-23744, 2014.

[66] A. Comotti, S. Bracco, P. Sozzani et al., "Nanochannels of two distinct cross-sections in a porous Al-based coordination polymer," Journal of the American Chemical Society, vol. 130, no. 41, pp. 13664-13672, 2008. 

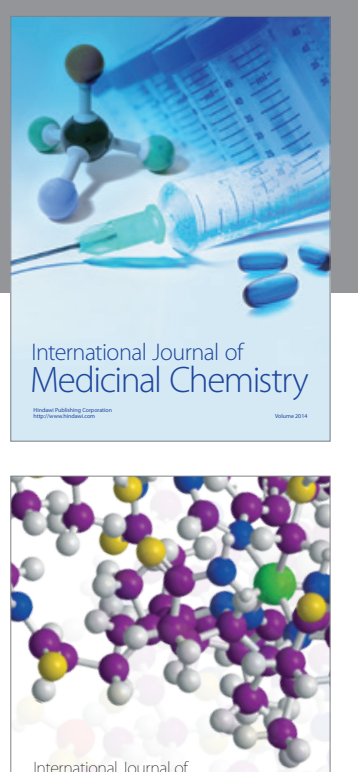

Carbohydrate Chemistry

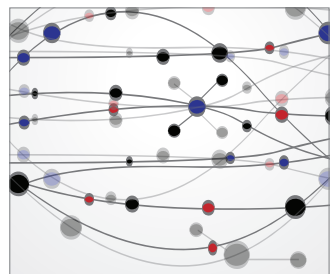

The Scientific World Journal
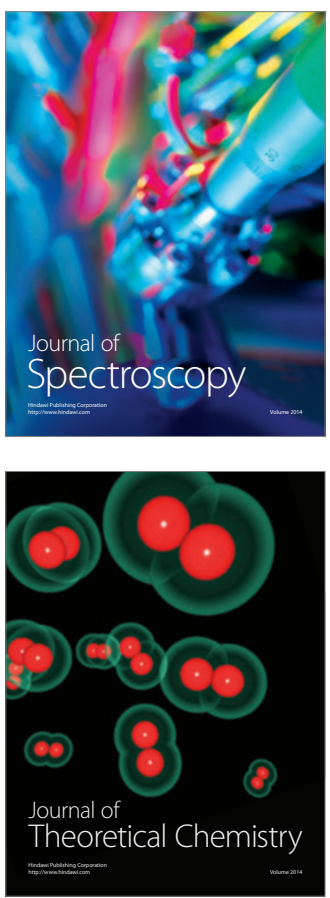
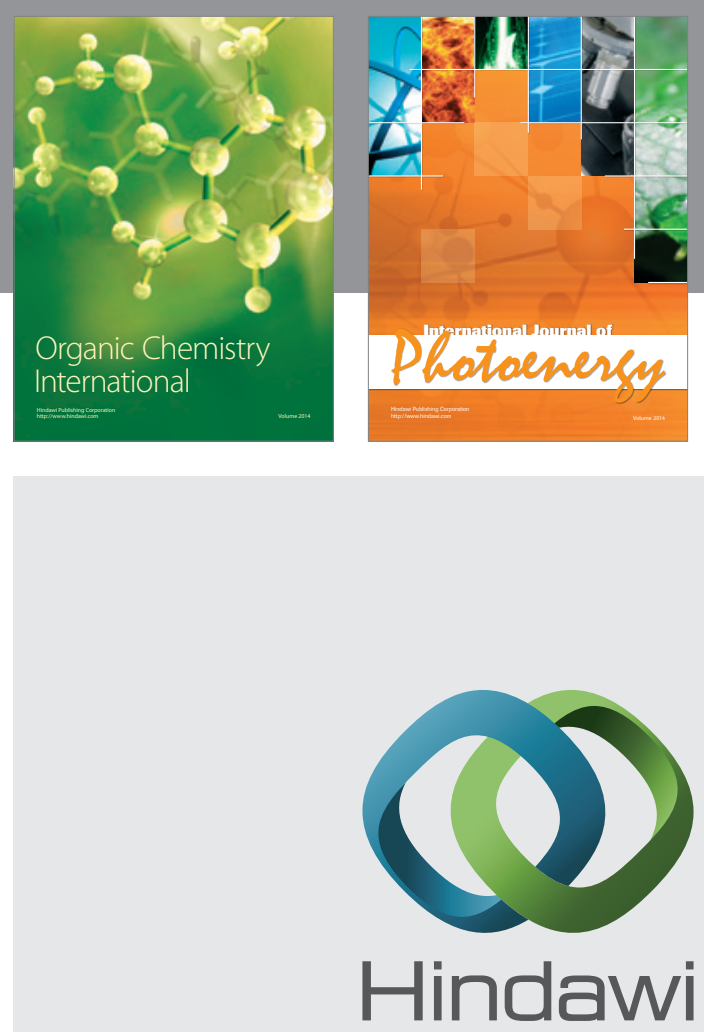

Submit your manuscripts at

http://www.hindawi.com

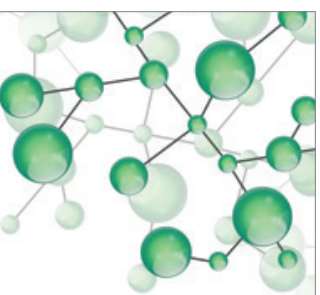

International Journal of

Inorganic Chemistry

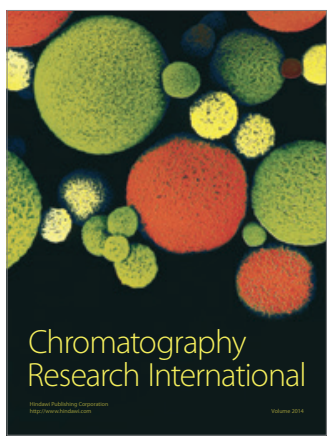

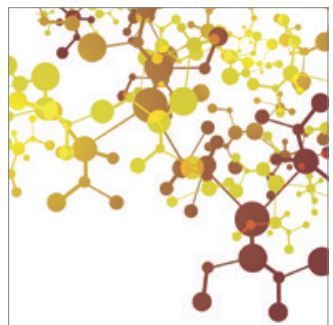

Applied Chemistry
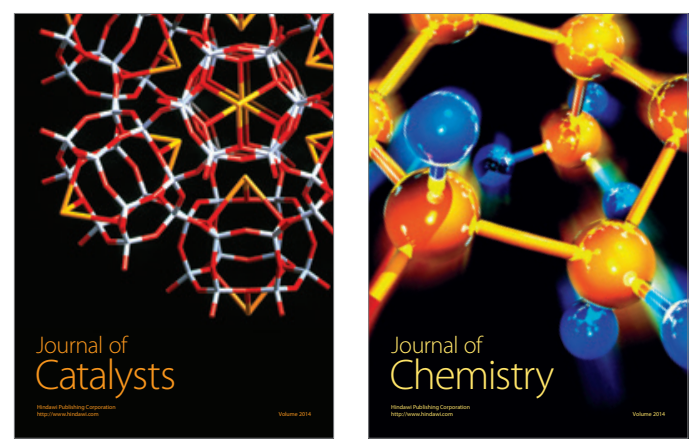
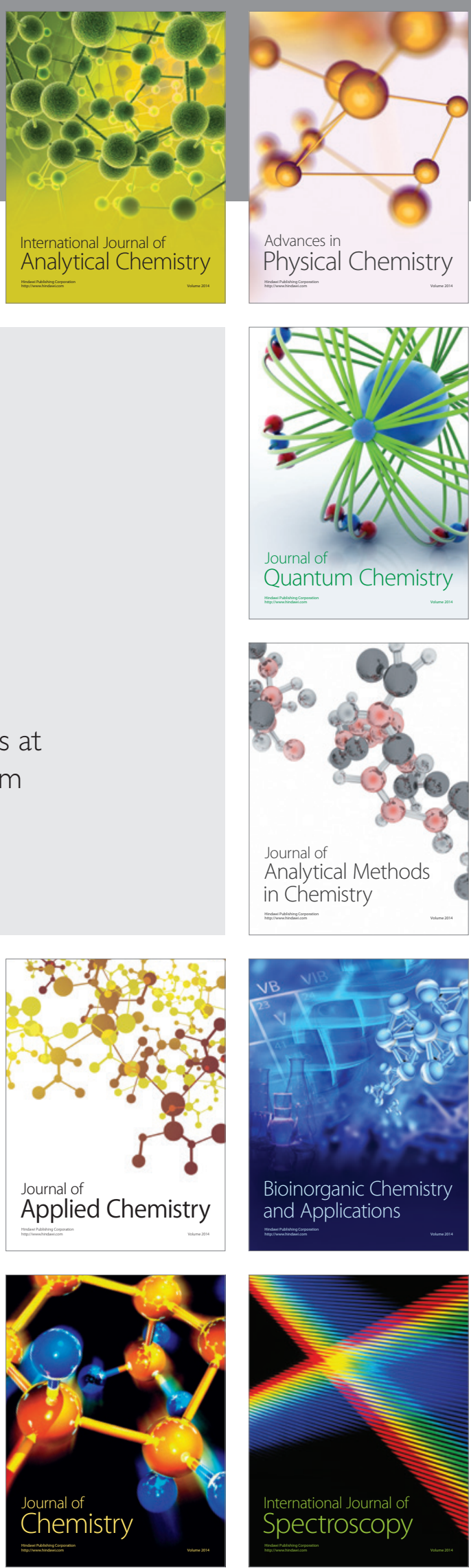